\title{
EFFECTS OF A COMPENSATORY DRY-LAND TRAINING PROGRAM ON SHOULDER POSTURE AND SCAPULAR POSITION OF COMPETITIVE FEMALE SWIMMERS
} João Paulo Sousa ${ }^{1,2}$, João Malta ${ }^{1,2}$, Ana Carrageta, ${ }^{1}$ Nuno Batalha ${ }^{1,2}$

${ }^{1}$ Departamento de Desporto e Saúde, Escola de Ciência e Tecnologia, Universidade de Évora (Portugal)

${ }^{2}$ Comprehensive Health Research Center (CHRC), Universidade de Évora (Portugal)

OPEN ACCES

Correspondencia João Paulo Sousa Pavilhão Gimnodesportivo de Universidade de Évora, Rua Reguencos de Monsaraz, ne14, 7000-727 Évora jsousa@uevora.pt 00351266769522

Funciones de los autores: Todos los autores trabajaron equitativamente en la consecución del trabajo

Recibido: $12 / 07 / 2019$ Aceptado: 01/09/2019 Publicado: 30/09/2019

Citación:

Sousa, J. P., Malta, J., Carrageta, A., \& Batalha, N. (2019). Effects of a compensatory dry-land training program on shoulder posture and scapular position

of competitive female swimmers. RIAA. Revista de Investigación en Actividades Acuáticas, 3(6), 45-52. https://doi.org/10.21134/riaa.v3i6.1833

@creative

Creative Commons Licens ta obra está bajo una licencia de Creative Commons ReconocimientoNoComercial-Compartir-Igua 4.0 Internacional
Background: Competitive swimmers place a significant demand on the shoulder adductors and internal rotator muscles due to the repetitive nature of swimming movements.

Objectives: To evaluate the effect of a compensatory dry-land training program on the shoulder posture and scapular position of competitive female swimmers

Method: 25 National Level female competitive swimmers received an 8-week intervention program focused on strengthening of posterior shoulder girdle muscles and stretching of anterior shoulder muscles. The study sample was exposed to a control period of 2 weeks and an intervention period of 8 weeks.

Results: Significant differences were found after the intervention period, on both dominant and non-dominant sides, with respect to shoulder protraction (distance between the anterior aspect of the acromion to the wall $-p<.05$ ) and scapular abduction (distance between a medial line marked over the thoracic spinal process and the medial border of spina scapulae $-p<.05$; and distance between a medial line marked over the thoracic spinal process and the medial border of the spina scapulae $-p<.05)$.

Conclusions: The results revealed that the incorporation of a compensatory dry-land training program alongside a normal in-water training significantly reduced the distance of shoulder posture in protraction and scapular position in abduction. Key words: shoulder protraction, scapular abduction, dry-land training, swimming, female.

Título: Efectos de un programa compensatorio de entrenamiento en tierra firme sobre la postura del hombro y la posición escapular de las nadadoras competitivas.

Antecedentes: los nadadores competitivos ejercen una demanda significativa en los aductores de hombro y los músculos rotadores internos debido a la naturaleza repetitiva de los movimientos de natación.

Objetivos: evaluar el efecto de un programa compensatorio de entrenamiento en tierra firme sobre la postura del hombro y la posición escapular de las nadadoras competitivas

Método: 25 nadadores competitivos femeninos de nivel nacional recibieron un programa de intervención de 8 semanas enfocado en el fortalecimiento de los músculos de la cintura escapular posterior y el estiramiento de los músculos anteriores del hombro. La amuestra fue expuesta a un período de control de 2 semanas y de intervención de 8 semanas. Resultados: Se encontraron diferencias significativas después del período de intervención, tanto en los lados dominantes como en los no dominantes, con respecto a la protracción del hombro (distancia entre la cara anterior del acromion a la pared $-p<.05$ ) y la abducción escapular (distancia entre una línea medial marcado sobre el proceso de la columna torácica y el borde medial de la espina escapulae $-p<.05$; y la distancia entre una línea medial marcada sobre el proceso de la columna torácica y el borde medial de la espina escapulae $-p<.05$ )

Conclusiones: Los resultados revelaron que la incorporación de un programa compensatorio de entrenamiento en tierra firme junto con un entrenamiento normal en el agua redujo significativamente la distancia de la postura del hombro en la protracción y la posición escapular en la abducción.

Palabras clave: protracción del hombro, abducción escapular, entrenamiento en tierra firme, natación, mujer.

Título: Efeitos de um programa compensatório de treino em terra firme na postura do ombro e na posição escapular de nadadoras competitivas

Contexto: Os nadadores de competição impõem uma exigência significativa aos músculos adutores e rotadores internos do ombro devido à natureza repetitiva dos movimentos de natação.

Objectivos: Avaliar o efeito de um programa compensatório de treinamento em terra firme na postura do ombro e na posição escapular de nadadoras competitivas

Método: 25 nadadoras competitivas de nível nacional receberam um programa de intervenção de 8 semanas focado no fortalecimento dos músculos posteriores da cintura escapular e no alongamento dos músculos anteriores do ombro. A amostra do estudo foi exposta a um período de controle de 2 semanas e de intervenção de 8 semanas.

Resultados: Diferenças significativas foram encontradas após o período de intervenção, nos lados dominante e não dominante, em relação à protração do ombro (distância entre o aspecto anterior do acrômio à parede - $p<0.05$ ) e abdução escapular (distância entre um linha medial marcada sobre o processo espinhal torácico e a borda medial da espinha escápula - $p<0.05$; e distância entre uma linha medial marcada sobre o processo espinhal torácica e a borda medial da espinha escápula $-p<0.05)$.

Conclusions: Os resultados revelaram que a incorporação de um programa compensatório de treino em terra firme juntamente com o treino normal na água reduz significativamente a distância da postura do ombro na protração e na posição escapular na abdução.

Palavras-chave: protração do ombro, abdução escapular, treinamento em terra firme, natação, feminino. 


\section{Introduction}

The training intensity in competitive swimming is very challenging, with the shoulder girdle requiring considerable muscular endurance because the upper extremities provide the large majority of the propulsive force (Pink \& Tibone, 2000). Excessive repetition of overhead movements and cumulative years of swimming training place a substantial strain on the shoulder girdle muscles with subsequent adaptations (Heinlein \& Cosgarea, 2010; Higson, Herrington, Butler, \& Horsley, 2018). Some movements require varying degrees of internal and external shoulder rotation along with scapular protraction and retraction (McLaine, Ginn, Fell, \& Bird, 2018).

Electromyographic studies have shown that shoulder adductors and internal rotator muscles are responsible for the producing major propulsive forces and sustain a significant burden because of the repetitive nature of swimming movements (Kluemper, Uhl, \& Hazelrigg, 2006; Pink, Perry, Browne, Scovazzo, \& Kerrigan, 1991). Therefore, during ordinary in-water practice, the shoulder adductor and the internal rotator (anterior shoulder girdle) muscles can become stronger and more effective in relation to the posterior shoulder muscle group (Kluemper et al., 2006). This is supported by several biomechanical studies that report an increase in internal rotator strength when compared to their antagonists (Batalha, Raimundo, Tomas-Carus, Barbosa, \& Silva, 2013; Habechian, Van Malderen, Camargo, \& Cools, 2018; Kluemper et al., 2006; Ramsi, Swanik, Swanik, Straub, \& Mattacola, 2004). While obviously beneficial to forward propulsion, enhanced adduction and internal rotation strength may result in muscle imbalance, which may decrease glenohumeral stability (Weldon \& Richardson, 2001). It is anticipated that an agonist-antagonist imbalance will stimulate the adoption of postural adaptations such as anterior shoulder displacement into protraction, as the posterior muscles are less efficient in pulling the scapulae towards the spine (Kluemper et al., 2006; Laudner, Wenig, Selkow, Williams, \& Post, 2015; McMaster, 1999; Peterson et al., 1997; Marilyn Pink \& Tibone, 2000; Tate et al., 2012).

The above-mentioned muscle imbalance and subsequent shoulder anteriorization may also result in glenohumeral internal rotation, downward rotation and scapular tilt. Some researchers state that the presence of stronger anterior shoulder girdle muscles may be responsible for postural adaptations that diminish the posterior tilt of the scapulae during the humerus elevation (Kluemper et al., 2006; Ludewig \& Cook, 2000). Shoulder pain can produce and predispose swimmers to subacromial impingement (Bak \& Faun $\varnothing, 1997$; Tate et al., 2012), and glenohumeral instability (Thigpen et al., 2010; Weon et al., 2010). Biomechanical studies suggest that significant changes in muscle activity, especially of scapular stabilizers and shoulder rotators, play an important role in the development of shoulder problems in the overhead athlete (Heinlein \& Cosgarea, 2010; Serenza et al., 2018).

Whenever the scapulae is displaced, it will adversely affect the posture of the shoulder, since the latter depends on the position of the scapulae (Kendall, McCreary, \& Provance, 2005). The scapulae provides stabilization of the glenohumeral joint during swimming (Pink et al., 1991). Therefore, anteriorization or protraction of the shoulder is a postural condition triggered by the adverse position of the scapulae in abduction and elevation. This condition can also be ascribed to shortening and shoulder muscle weakness (Kendall et al., 2005; Ruivo, Pezarat-Correia, \& Carita, 2014).

Over the years, some modifications in competitive swimming training have been made, including more comprehensive compensatory training programs (Tate et al., 2012). However, in addition to several researchers reporting on the advantages of strengthening of posterior muscles and stretching anterior muscles to decrease agonist-antagonist muscular imbalance and correct the posture of shoulder protraction
(Hajihosseini, Norasteh, Shamsi, \& Daneshmandi, 2014; Kendall et al., 2005; Kluemper et al., 2006; Laudner et al., 2015), ideal methods still need to be identified and disseminated. This information can help a on the implementation of these strategies to reduce the possibility of injury in competitive swimming.

Therefore, the purpose of this study was to determine the effects of an 8-week compensatory dry-land training program on the shoulder posture and scapular position of competitive female swimmers. The intervention focused on the strengthening of the posterior shoulder girdle muscles and the stretching of the anterior shoulder girdle muscles.

\section{Methods}

\section{Design}

A one-group pre-test post-test design. The study sample was exposed to a control period of 2 weeks and an intervention period of 8 weeks. The control period included an initial evaluation (baseline), followed by 2 weeks of normal in-water training activities, and a final (pre-test) evaluation. The intervention period started with the pre-test evaluation, followed by 8 weeks of a compensatory dry-land training program alongside normal in-water training activities, and a final (posttest) evaluation (Figure 1).

Figure 1. Study Diagram.

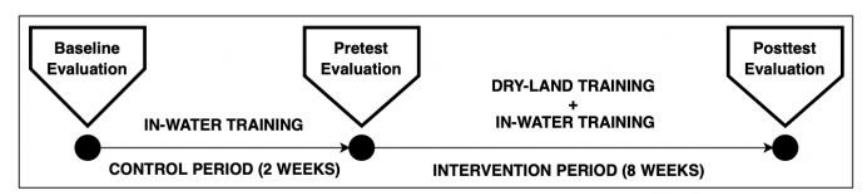

\section{Participants}

A total of twenty-five National Level competitive female swimmers agreed to participate in this study. None of the swimmers was excluded during the intervention period. Descriptive statistics for the study group are listed in Table 1.

Table 1. Sample details $(n=25)$.

\begin{tabular}{|l|c|c|c|c|}
\hline Variables & Mean & SD & Min & Max \\
\hline Age $(\mathrm{y})$ & 14,12 & 1,45 & 12 & 17 \\
\hline Height $(\mathrm{cm})$ & 161,88 & 4,66 & 151 & 170 \\
\hline Weight $(\mathrm{kg})$ & 56,76 & 8,04 & 43 & 74 \\
\hline BMI & 21,60 & 2,49 & 16,38 & 25,71 \\
\hline
\end{tabular}

To be included, female swimmers should be engaged in in-water training for at least 4 hours per week and have two years of swimming experience. Swimmers were also included if they had no limitations in in-water and dry-land training as a result of shoulder pain. Those who had been treated for shoulder pain (including surgery) or had been engaged in specific shoulder exercise training within the previous 6 months were excluded from the study.

Swimmers were also excluded if they missed the in-water training for three consecutive days or more due to shoulder pain. They also were excluded if they missed the compensatory dry-land training for two consecutive days or more due to shoulder pain.

Before data collection, all swimmers read and signed a consent form approved by the Ethics Committee of the seeding Institution (proceeding GD/33839/2014). Swimmers under 18 of age had their parents or legal guardians to sign the consent form. 


\section{Measurement Protocol}

The measurement protocol was adapted from the techniques used by several authors (Carvalho et al., 2019; Juul-Kristensen, Hilt, Enoch, Remvig, \& Sjøgaard, 2011; Kluemper et al., 2006; Larsen, Søgaard, Eshoj, Ingwersen, \& Juul-Kristensen, 2019; Laudner et al., 2015; Peterson et al., 1997). All evaluations were completed at the beginning of a regular competitive season. Both shoulders and scapulae of each swimmer, despite dominant laterality and in a randomised order, were measured with the double square device (Johnson Level Tool 420EM-S 16, USA) and a palpation meter (PALM Performance Attainment Associate, St. Paul, MN, USA) on three moments (baseline, pre-test, and post-test), by the same researcher. No attempt was made to provide a diagnostic of shoulder protraction, scapular abduction or scapular upward rotation. The research team only focused on measuring the modifications on obtained distances.

The double-square device was used to measure the distance, in millimetres, from the anterior aspect of the acromion to the wall, Acromion to Wall Index (AWI), which is often associated with shoulder posture in protraction (Carvalho et al., 2019). Through palpation, with the help of an experienced anatomist, the anterior aspect of acromion was identified and marked. The swimmer was instructed to stand with his back against the wall and assume a standing resting position by relaxing into his normal posture. This resting position was used to prevent conscient postural correction. At this point, the double square device was positioned over the swimmers' shoulder and the distance between the wall and the anterior aspect of the acromion was measured and recorded. Each distance was recorded 3 times, with the average used for analysis. The same procedure was carried out by the research team on both shoulders on baseline, pre-test and post-test evaluations. The mean and standard deviation of all measurements was used for statistical analysis.

A palpation meter was used to measure the closest perpendicular distance, in millimetres, between the inferior angle of the scapula and the corresponding spinous process of the thoracic vertebrae during rest, Lower Horizontal Distance (LHD), and the closest perpendicular distance, in millimetres, between the root of the spine of the scapula and the corresponding spinous process of the thoracic vertebrae during rest, Upper Horizontal Distance (UHD). Both distances are often associated with the scapular position in abduction and/or upward rotation (Figure 2 ).

Figure 2. Scapular position distances (UHD and LHD).

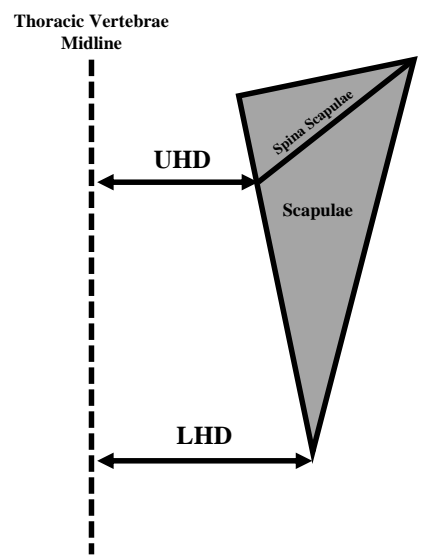

Through palpation, with the help of an experienced anatomist, a medial line was marked over the thoracic spinal process, the medial border of the spina scapulae and the inferior angle of the scapulae were identified and also marked. The swimmer was instructed to stand in a resting position by relaxing into his normal posture. This resting position was used to prevent conscient postural correction. At this point, the palpation meter was positioned on the swimmers' medial line over the thoracic spinal process and the closest perpendicular distances to the medial border of the spina scapulae and inferior angle of the scapulae were measured and recorded. Each distance was recorded 3 times, with the average used for analysis. The same procedure was carried out by the research team on both scapulae on baseline, pre-test and post-test evaluations. The mean and standard deviation of all measurements was used for statistical analysis.

\section{Reliability}

A pilot study was performed to determine the intra-rater reliability of the measuring devices. All measuring procedures were performed twice by the same researcher with the double square device and palpation meter, on 5 swimmers with an interval of 7 days between evaluations. Measurements were found to be reliable with intraclass correlation coefficient (ICC) values superior to .91 for both devices. Some authors also obtained ICC values above .89 for shoulder posture (Carvalho et al., 2019; Kluemper et al., 2006; Peterson et al., 1997) and above .67 for scapular position (Larsen et al., 2019).

\section{Intervention Protocol}

Following the measurement protocol, swimmers began an 8-week compensatory dry-land training program that was adapted from Kluemper et al. (2006) and Peterson et al. (1997). The training program contained five exercises that could facilitate modifications in shoulder protraction, scapular abduction and scapular upward rotation related distances. These exercises were performed 3 times per week, after the regular in-water training activities ( 6 days a week), focusing on the strengthening of posterior shoulder girdle muscles and stretching of the anterior shoulder girdle muscles (pectoralis major and pectoralis minor muscles). All proposed exercises respected the principles of progression ensuring that the body was adapting and requiring overload. Details regarding the progression of each exercise are depicted in Table 2.

Table 2. Exercise progression during 8 weeks of intervention.

\begin{tabular}{|c|c|c|c|}
\hline $\begin{array}{l}1^{\text {st }} / 2^{\text {nd }} \\
\text { Week }\end{array}$ & $\begin{array}{l}3^{\text {rd }} / 4^{\text {th }} \\
\text { Week }\end{array}$ & $\begin{array}{l}5^{\text {th }} / 6^{\text {th }} \\
\text { Week }\end{array}$ & $\begin{array}{l}7^{\text {th }} / 8^{\text {th }} \\
\text { Week }\end{array}$ \\
\hline \multicolumn{4}{|c|}{ Thera-Band 1 \& Thera-Band 2} \\
\hline Green Band & Green Band & Black Band & Black Band \\
\hline 15 reps & 20 reps & 15 reps & 20 reps \\
\hline 3 sets & 3 sets & 3 sets & 3 sets \\
\hline 15 s rest & 15 s rest & 15 s rest & 15 s rest \\
\hline \multicolumn{4}{|c|}{ Wall-bar } \\
\hline 5 sec hold & $10 \mathrm{sec}$ hold & $15 \mathrm{sec}$ hold & $20 \mathrm{sec}$ hold \\
\hline 3 sets & 3 sets & 3 sets & 3 sets \\
\hline 20 s rest & 30 s rest & 40 s rest & 60 s rest \\
\hline \multicolumn{4}{|c|}{ Passive Stretch 1 \& Passive Stretch 2} \\
\hline $15 \mathrm{sec}$ hold & $20 \mathrm{sec}$ hold & $25 \mathrm{sec}$ hold & $25 \mathrm{sec}$ hold \\
\hline 3 sets & 3 sets & 3 sets & 3 sets \\
\hline 15 s rest & 15 s rest & 15 s rest & 15 s rest \\
\hline
\end{tabular}

The strengthening of the posterior shoulder girdle muscles included three exercises, two with Thera-Band ${ }^{\circledR}$ elastic bands and one with the use of wall bars (Table 3 ). The intention was to promote scapular adduction (retraction) and external rotation of the glenohumeral joint. 
Table 3. Strengthening of the posterior shoulder girdle muscles.

\section{Thera-Band Exercise 1 (TB1)}

The Thera-band is held in tension between both hands. The arm is placed vertically and close to the trunk with 90 o of elbow flexion. With the forearms in pronation and a horizontal position, the swimmer is asked to externally rotate the shoulder and adduct the scapulae (concentric component). The swimmer then executes a controlled return to the starting position (eccentric component).

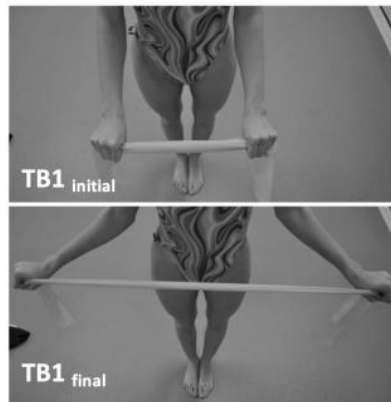

Thera-Band Exercise 2 (TB2)

The Thera-band is held in tension between the fixed point in front of the swimmer and the hands. The arm is placed at 90 o of shoulder abduction and 90 o of elbow flexion. With the forearms in pronation in a horizontal position, the swimmer is asked to externally rotate the shoulder into a vertical position (concentric component). The swimmer then executes a controlled return to the starting position (eccentric component).

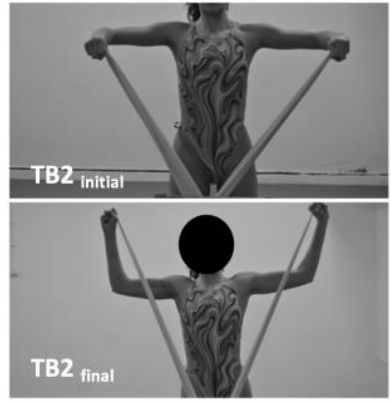

Wall-Bar Exercise (WB

Both hands firmly gripping the wall-bar and the lower limbs supporting the weight of the body on the lower-bar. The shoulder is slightly abducted in the scapular plane. The elbows in full flexion. With the forearms in pronation, the swimmer is asked to adduct the arms, medially retract the scapulae, support the weight of the body with the hand-grip, and place the shoulders at the level of the hand-grip bar. The position is maintained isometrically during the desired seconds according to the training program (isometric component). The swimmer then executes a controlled return to the starting position (eccentric component).
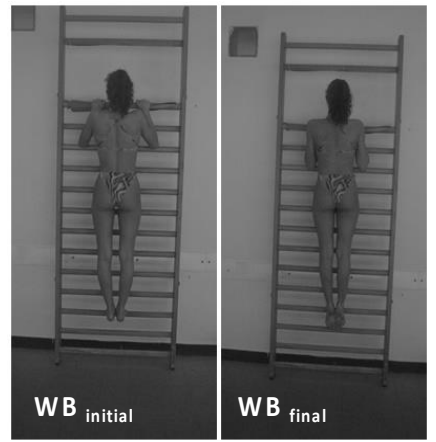

Two stretching exercises were included that focused on the passive stretching of anterior shoulder girdle muscles such as the pectoralis minor (PS1) and the pectoralis major (PS2). The intention was to reduce the shortening of the anterior muscles. The stretching procedures were always executed by the same researcher and are described in Table 4.

Table 4. Stretching exercises.

\section{Pectoralis Minor Passive Stretch (PS1)}

The swimmer is in a supine position, on a gym mat, with a foam roll placed on is back. The researcher holds the swimmer shoulders and slowly presses down against the gym mat. The position is maintained during the desired seconds according to the training program. The researcher then releases the shoulder hold and enables a controlled return to the starting position.

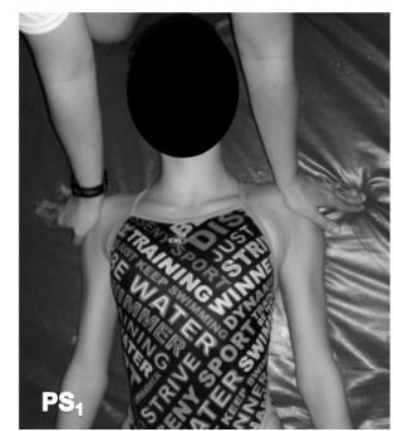

\section{Pectoralis Major Passive Stretch (PS2)}

The swimmer is in a kneeling position and the researcher is standing behind. The fingers are laced together behind the head. Standing behind the swimmer, the researcher places his hands on both elbows, pulling them backward in a diagonal direction. The position is maintained during the desired seconds according to the training program. The researcher then releases the hold and enables a controlled return to the starting position.

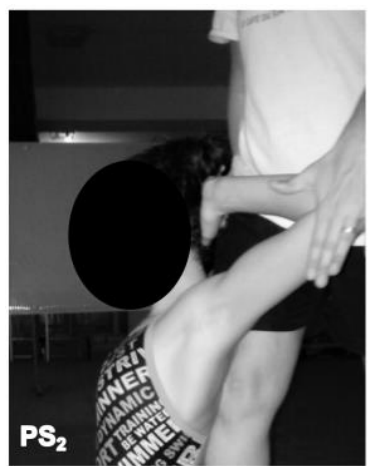

For each Thera-Band exercise, participants had a period of adaptation to the yellow elastic band (reduced tension). For the wall-bar exercise, the period of adaptation included the use of the lower limb support. The purpose of this adaptation period was to ensure that the correct technique was being applied. After the adaptation period, all swimmers used the green elastic band for 4 weeks and the black elastic band for the remaining 4 weeks.

\section{Statistical Analysis}

Statistical analysis was performed using SPSS Statistics ${ }^{\circledR}$ (IBM SPSS Statistics Version 25, New York, USA). Data are reported as mean and standard deviations. Comparisons were made between periods of evaluation using $t$-Tests or Wilcoxon signed-rank tests. For all analysis, the level of significance was set at .05. The mean difference and effect size between the baseline, pre-test, and post-test were also calculated. 
The clinical importance and the dimension of the effect followed the suggestions from Cohen (1988), with an effect size of 0.2 or less considered small, 0.5 considered moderate, and above 0.8 considered large.

Results

\section{Control Period}

During the control period of 2 weeks with normal in-water training activities, descriptive statistics for shoulder posture and scapular position distances are displayed in Table 5 and 6 . The analysis revealed that the control period did not elicit a statistically significant change, between baseline to pre-test despite dominance, in AWI $\left(t_{(24)}=-0.822, p\right.$ $=0.419$ and $\left.t_{(24)}=1.934, p=0.065\right)$. Indeed, between baseline to pretest despite dominance, mean difference values for AWI $(0.65 \mathrm{~mm}$ and $-0.71 \mathrm{~mm}$ ) indicate no significant changes in the distance related to shoulder posture.

Further analysis also revealed that the control period did not elicit statistically significant changes, between baseline to pre-test despite dominance, in UHD $(Z=-1.633, p=0.102$ and $Z=-0.447, p=0.655)$ and IAS $(Z=-0.272, p=0.785$ and $Z=-1.089, p=0.276)$. Indeed, between baseline to pre-test despite dominance, mean difference values for UHD $(-0.23 \mathrm{~mm}$ and $-0.40 \mathrm{~mm})$ and LHD $(-0.04 \mathrm{~mm}$ and $0.36 \mathrm{~mm})$ indicate no significant changes in the distances related to scapular position.

Table 5. Shoulder Posture - AWI distances (control period).

\begin{tabular}{|l|c|c|}
\hline & \multicolumn{2}{|c|}{ AWI Distances } \\
\hline & $\begin{array}{c}\text { Dominant } \\
\text { (mean } \pm \text { SD) }\end{array}$ & $\begin{array}{c}\text { Non dominant } \\
\text { (mean } \pm \text { SD) }\end{array}$ \\
\hline Baseline $(\mathrm{mm})$ & $77,20 \pm 9,86$ & $78,57 \pm 10,85$ \\
\hline Pre-test $(\mathrm{mm})$ & $77,85 \pm 11,19$ & $77,87 \pm 10,47$ \\
\hline Diff $(\mathrm{mm})$ & $0,65 \pm 3,89$ & $-0,71 \pm 1,79$ \\
\hline Effect Size & 0,07 & $-0,07$ \\
\hline$p$-value & .419 & .065 \\
\hline
\end{tabular}

Table 6. Scapular Position - UHD and LHD distances (control period)

\begin{tabular}{|l|c|c|c|c|}
\hline & \multicolumn{2}{|c|}{ UHD distances } & \multicolumn{2}{c|}{ LHD distances } \\
\hline & $\begin{array}{c}\text { Dominant } \\
\text { (mean } \pm \text { SD) }\end{array}$ & $\begin{array}{c}\text { Non dominant } \\
\text { (mean } \pm \text { SD) }\end{array}$ & $\begin{array}{c}\text { Dominant( } \\
\text { mean } \pm S D)\end{array}$ & $\begin{array}{c}\text { Non dominant } \\
\text { (mean } \pm S D)\end{array}$ \\
\hline Baseline $(\mathrm{mm})$ & $62,39 \pm 5,77$ & $62,00 \pm 6,61$ & $80,84 \pm 4,97$ & $80,44 \pm 4,16$ \\
\hline Pre-test $(\mathrm{mm})$ & $62,16 \pm 5,73$ & $61,60 \pm 6,24$ & $80,80 \pm 4,49$ & $80,80 \pm 4,25$ \\
\hline Diff $(\mathrm{mm})$ & $-0,23 \pm 0,98$ & $-0,40 \pm 3,14$ & $-0,04 \pm 1,43$ & $0,36 \pm 1,38$ \\
\hline Effect Size & $-0,04$ & $-0,06$ & $-0,01$ & 0,09 \\
\hline$p$-value & .102 & .655 & .785 & .276 \\
\hline
\end{tabular}

Note: UHD - Distance between the inferior angle of the scapula and the

corresponding spinous process of the thoracic vertebrae, during rest; LHD - distance between the root of the spine of the scapula and the corresponding spinous process of the thoracic vertebrae

\section{Intervention Period}

Concerning the intervention period of 8 weeks with normal in-water training activities alongside a compensatory dry-land training program, descriptive statistics for shoulder posture and scapular position distances are displayed in Table 7 and 8.

The analysis revealed that the intervention period did elicit a statistically significant change, between pre-test and post-test despite dominance, in AWI $\left(t_{(24)}=-13.110, p=0.000\right.$ and $\left.t_{(24)}=13.419, p=0.000\right)$ (Figure 3 ). Indeed, between pre-test and post-test, mean difference values for AWI $(D=-19.92 \mathrm{~mm}$ and $N D=-19.55 \mathrm{~mm})$ indicate a significant decrease in the distance related to shoulder protraction.

Further, Cohen's effect size values on dominant $(d=-1.78)$ and nondominant $(d=-1.87)$ sides suggest a high significance.

Table 7. Shoulder Posture - AWI distances (intervention period).

\begin{tabular}{|l|c|c|}
\hline & \multicolumn{2}{|c|}{ AWI Distances } \\
\hline & $\begin{array}{c}\text { Dominant } \\
\text { (mean } \pm \text { SD) }\end{array}$ & $\begin{array}{c}\text { Non dominant } \\
\text { (mean } \pm \text { SD) }\end{array}$ \\
\hline Pre-test $(\mathrm{mm})$ & $77,85 \pm 11,19$ & $77,87 \pm 10,47$ \\
\hline Post-test $(\mathrm{mm})$ & $57,93 \pm 8,42$ & $58,32 \pm 8,32$ \\
\hline Diff $(\mathrm{mm})$ & $-19,92 \pm 7,44$ & $-19,55 \pm 7,14$ \\
\hline Effect Size & $-1,78$ & $-1,87$ \\
\hline$p$-value AWI - distance from the anterior aspect of the acromion to the wall;
\end{tabular}

$*$ significant difference between pre-test and post-test with parametric testing ( $\mathrm{t}$-Test for paired samples)

Table 8. Scapular Position - UHD and LHD distances (intervention period)

\begin{tabular}{|l|c|c|c|c|}
\hline & \multicolumn{2}{|c|}{ UHD distances } & \multicolumn{2}{c|}{ LHD distances } \\
\hline & $\begin{array}{c}\text { Dominant } \\
\text { (mean } \pm \text { SD) }\end{array}$ & $\begin{array}{c}\text { Non dominant } \\
\text { (mean } \pm \text { SD) }\end{array}$ & $\begin{array}{c}\text { Dominant } \\
\text { (mean } \pm \text { SD) }\end{array}$ & $\begin{array}{c}\text { Non dominant } \\
\text { (mean } \pm \text { SD) }\end{array}$ \\
\hline Pre-test $(\mathrm{mm})$ & $62,16 \pm 5,73$ & $61,60 \pm 6,24$ & $80,80 \pm 4,49$ & $80,80 \pm 4,25$ \\
\hline Post-test $(\mathrm{mm})$ & $59,20 \pm 5,89$ & $58,80 \pm 5,45$ & $76,80 \pm 4,30$ & $77,12 \pm 5,15$ \\
\hline Diff $(\mathrm{mm})$ & $-2,96 \pm 5,13$ & $-2,80 \pm 5,49$ & $-4,00 \pm 3,74$ & $-3,68 \pm 4,22$ \\
\hline Effect Size & $-0,52$ & $-0,45$ & $-0,89$ & $-0,87$ \\
\hline$p$-value & $.015^{*}$ & $.025^{*}$ & $.000^{*}$ & $.001^{*}$ \\
\hline
\end{tabular}

UHD - Distance between the inferior angle of the scapula and the corresponding spinous process of the thoracic vertebrae, during rest; LHD - distance between the root of the spine of the scapula and the corresponding spinous
process of the thoracic vertebrae; ${ }^{*}$ significant difference between pre-test and post-test with non-parametric testing (Wilcoxon for 2 related samples)

Additional analysis also revealed that the intervention period did elicit statistically significant changes, between pre-test and post-test despite dominance, in UHD $(Z=-2.441, p=0.015$ and $Z=-2.248, p=0.025)$ and $\operatorname{LHD}(Z=-3.601, p=0.000$ and $Z=-3.471, p=0.001)$ (Figure 4 and 5$)$.

Figura 3. AWI Distance (*significant differences from pre-test with $p<.05$ ).

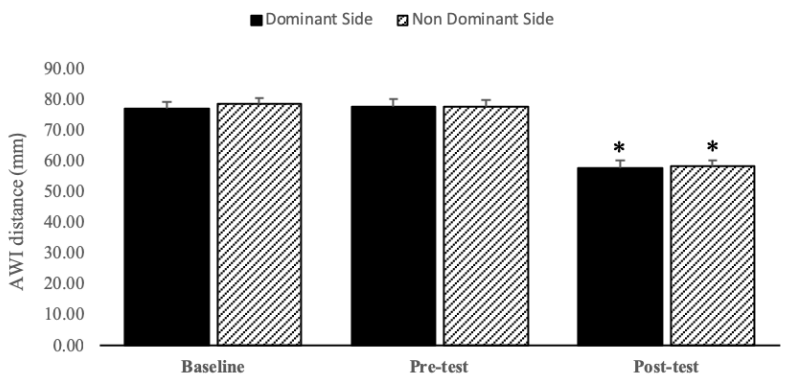

Figura 4. UHD Distance ( $*$ significant differences from pre-test with $p<.05$ ).

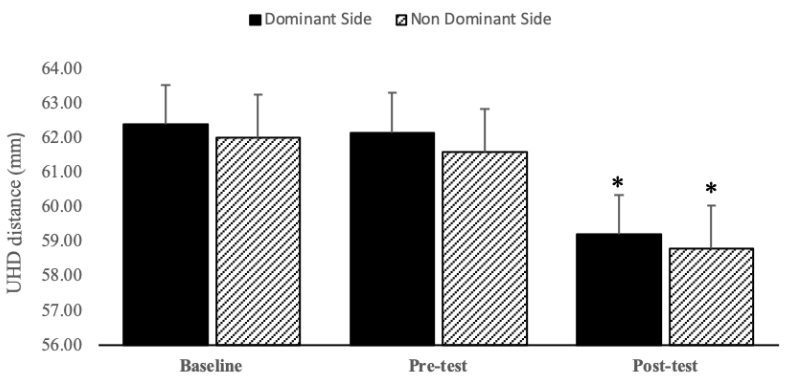


Figura 5. LHD Distance (*significant difference from pre-test with $p<.05$ ).

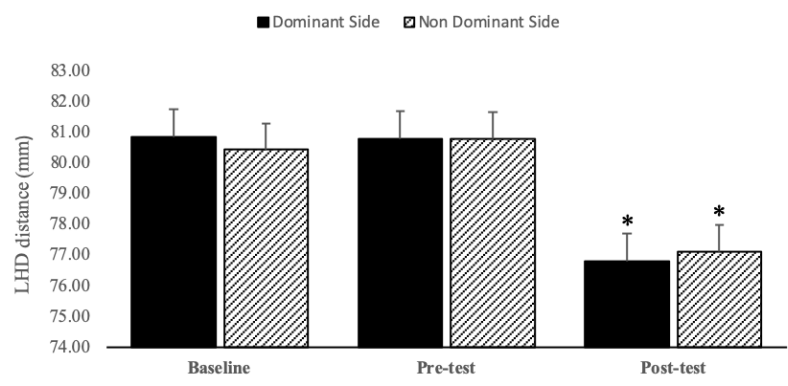

Indeed, between pre-test and post-test, mean difference values for UHD $(-2.96 \mathrm{~mm}$ and $-2.80 \mathrm{~mm})$ and LHD $(-4.00 \mathrm{~mm}$ and $3.86 \mathrm{~mm})$ indicate a significant decrease in the distances related to scapular abduction. The Cohen's effect size values on dominant $(d=-0.52)$ and nondominant $(d=-0.45)$ sides for UHD suggest a moderate significance, while for LHD on dominant $(d=-0.89)$, and non-dominant $(d=-0.87)$ sides suggest a high significance.

\section{Discussion}

This study evaluated the effects of an 8-week compensatory dry-land training program on the shoulder posture and scapular position of female competitive swimmers. The findings of the present study revealed that the female competitive swimmers experienced a significant reduction in shoulder protraction and scapular abduction distances after the intervention period.

Although swimming is considered to be a symmetric sport, differences in external rotation strength on the dominant shoulder is reported in the literature (Beach, Whitney, \& Dickoff-Hoffman, 1992; Gozlan et al., 2006). However, we did not find significant differences between overall shoulder posture and scapular position distances related to dominant laterality. The postural adaptations appear to have developed symmetrically, which may be explained by the fact that a large majority of our sample had a bilateral breathing pattern. Also, our exercises focused on maintaining scapular symmetry rather than muscle strength or endurance.

Our study had a very high level of study compliance that might account for our overall results. All swimmers came from the same swim team and were supervised by the same coach. The researcher supervised each exercise session. The high compliance enabled the research team and coach to closely monitor the compensatory dry-land training program. If a swimmer missed a training session, the coach would require a reposition on the same day or at the practice session on the following morning.

The measurement protocol for shoulder posture and scapular position was adapted from the techniques used by several authors (Carvalho et al., 2019; Juul-Kristensen et al., 2011; Kluemper et al., 2006; Larsen et al., 2019; Laudner et al., 2015; Peterson et al., 1997). All measurements were taken in static conditions rather than during the shoulder motion. However, other authors report that static measures produce very similar results when compared to dynamic measures and that many functional activities are performed with the shoulder in a static position (Wang, McClure, Pratt, \& Nobilini, 1999).

The intra-rater reliability of the double square device and the palpation meter was found to be high for both measuring devices, concerning scapular posture and scapular position distances. Some strategies adopted by the research team facilitated the high reliability of measurements. Bony landmarks can be difficult to identify due to increased muscle mass in swimmers, an experienced anatomist trained the evaluating researcher to ensure correct identification. Each distance was recorded 3 times, and, on each measuring position, swimmers were also asked to assume a standing resting position by relaxing into his normal posture to avoid conscious correction.

The included exercises of the compensatory dry-land training program were selected based on previous research (Kluemper et al., 2006; Peterson et al., 1997). We selected five exercises that could facilitate modifications in shoulder protraction, scapular abduction and scapular upward rotation related distances. These exercises were performed 3 times per week, after the regular in-water training activities. This could have affected the strength component of some dry-land exercises due to fatigue. However, no literature was found that could justify the execution of a compensatory training program before the in-water training. In addition, some literature mentions that fatigue of the muscles responsible for scapular adduction (retraction) may lead to additional protraction (Su, Johnson, Gracely, \& Karduna, 2004; Van de Velde, De Mey, Maenhout, Calders, \& Cools, 2011). Our results demonstrated a reduction in scapular adduction distance, which can indicate that fatigue was not present on our study sample.

Those engaged in competitive swimming place on their shoulders and scapulae a tremendous amount of stress. Swimmers are known to have postural adaptations linked to scapular kinematics, such as forward head, rounded shoulders, and increased thoracic kyphosis (Wang et al., 1999). They also tend to increase their shoulder internal rotation and adduction strength because of the pectoralis major and latissimus dorsi contribution during the swimming stroke (Bak \& Faun $\varnothing, 1997$; Beach et al., 1992; McMaster, 1999). Muscle imbalance may occur owing to the increased recruitment of internal rotators during swimming (Johnson, Gauvin, \& Fredericson, 2003) and stress at the glenohumeral capsular ligaments, which cause instability and may change the muscle ability to produce strength (O'Donnell, Bowen, \& Fossati, 2005). Due to the need for muscle endurance and the risk for shoulder disorders, swimmers may benefit from a exclusive shoulder-training program (Van de Velde et al., 2011).

Muscle imbalance can emerge in young swimmers within a period of 3 years of practice (Habechian et al., 2018). It is essential to promote an early balance between the glenohumeral and scapulothoracic muscles, with a specific focus on the strengthening of external rotators, supraspinatus and lower trapezius, so as to avoid shoulder disorders in these athletes (Hibberd, Oyama, Spang, Prentice, \& Myers, 2012; Van de Velde et al., 2011). Therefore, our strengthening exercises intended to promote scapular adduction and external rotation of the glenohumeral joint to counteract this tendency. The question arises, however, as to whether this modified muscle balance could be an adaptation or a potential risk factor for injury. In order to identify potential risk factors, prospective studies with larger groups of swimmers are needed.

The stretching exercises focused on the passive stretching of the pectoralis minor and the pectoralis major muscles. Since swimmers develop increased scapular protraction and elevation, our intention was to reduce the shortening of the anterior shoulder girdle muscles to counteract the effects of swimming on muscle-tightness development. The stretching strategy implemented on our study was adapted from Kluemper et al. (2006) and Hibberd et al. (2012). In order to reduce the increasing scapular protraction, attention was placed on the stretching of the pectoralis major and pectoralis minor (Hibberd et al., 2012; Johnson et al., 2003; Weldon \& Richardson, 2001).

The results of the current study show that the 8-week compensatory dry-land training program, with strengthening and stretching components, was able to produce a significant reduction on shoulder protraction and scapular upward rotation distances with a high significance effect size. For the scapular abduction, the reduction was 
also significant, but the effect size was moderate in significance. Some studies support our results of a reduction in shoulder protraction distance through stretching and strengthening exercises (Hajihosseini et al., 2014; Kluemper et al., 2006; Laudner et al., 2015; Roddey, Olson, \& Grant, 2002; Wang et al., 1999). In swimmers, Kluemper et al. (2006) found a decrease in shoulder protraction posture following a 6-week intervention, which included stretching of the anterior shoulder muscles and strengthening of the posterior shoulder muscles. Using 6 weeks of muscle-energy techniques on the pectoralis minor of asymptomatic swimmers, Laudner et al. (2015) found improvements on forward scapular posture. With a similar period of 6 weeks, applying a stretching and strengthening program, Hajihosseini et al. (2014) also found an improvement in the angle of forward shoulder posture. Additionally, on samples of asymptomatic subjects, Roddey et al. (2002) found a decrease in shoulder protraction following a 2-week pectoralis stretching program. Wang et al. (1999) found a decrease in scapular upward rotation after an exercise program in with forward shoulder posture.

The choice of using elastic bands for the strengthening program might give a notion that it was not challenging enough to a highly competitive and highly trained athlete (Lynch, Thigpen, Mihalik, Prentice, \& Padua, 2010). However, the exercise progression focused on always maintaining an optimal scapular symmetry rather than concentrating on muscle strength or endurance. A traditional in-water training program is expected to have high loads of stroke repetition and swam distances (Bak \& Faun $\varnothing, 1997$; Beach et al., 1992; McMaster, 1999). Proposing a compensatory exercise program to further increase the muscular load could have increased the risk of localized fatigue.

There are several inherent limitations in this study. A one-group convenience sample was used for this study. Random sampling with experimental and control groups for comparing results would have been ideal. However, swimmers were selected from only one swim team since the research team wanted to guarantee that they had identical in-water training activities implemented by the same coach thus avoiding biases from the different training regimens. Because swimmers followed the same in-water training activities the number of strokes, different styles and distances were not recorded. Furthermore, only female swimmers were recruited to minimize any effects due to sex.

Our study included a relatively small sample of swimmers, due to the option of having access to only one swim team. Adequate statistical power for detecting significant differences in outcome measures could be questioned. However, the observed changes resulted in moderate to large effect sizes, which suggest some clinical significance.

An intervention involving elastic bands possesses intrinsic limitations. The individual effort could not be assessed, and the elastic band length was not measured. Therefore, the exact amount of resistance provided is not known. An attempt was made to control this issue by clearly instructing the swimmers to maintain an initial tension that would correspond to a specific percentage of their perceived maximum strength and focus on the technical execution of the exercise.

In addition, because the final evaluation was taken immediately after the end of the intervention period, we cannot comment on the durability of the adaptations because a follow-up period was not implemented. It would have been beneficial to understand how long the reduction in shoulder protraction and scapular abduction would subsist. A suggestion is made to further monitor the distance reduction during a follow-up period to understand whether the effects are transient or progressive.

Finally, our intervention and data collection were carried out in the first half of the season, with less intense training and competition. Our swimmers had the pre-test evaluation on the beginning of October, while the swim training load was still low. At the time of post-test in December, the peak of most competitive swimming seasons, subjects were at the highest load of swim training. This increase in training load may account for the decrease in distances related to the shoulder posture and scapular position. Any effects of the intervention might have been masked (Lynch et al., 2010). In the future, an option could be made to continue the intervention program throughout the season, which may result in greater improvements in shoulder posture and scapular position (Hibberd et al., 2012).

\section{Conclusions}

The results from this study revealed that the incorporation of compensatory dry-land training program alongside a normal in-water training significantly reduced the shoulder protraction posture and scapular abduction position distances, despite dominance. From the presently available evidence and results from this study, it is suggested that the inclusion of strengthening of posterior shoulder girdle muscles and stretching of anterior shoulder muscles, as a compensatory dryland training approach, might be useful to reduce or avoid shoulder and scapular postural adaptations.

Further research is still necessary with larger groups and both sexes to understand the amplitude of the adaptations on shoulder posture and scapular position and whether these compensatory dry-land training interventions are capable of reducing the prevalence of shoulder pain and injury amongst swimmers.

\section{References}

Bak, K., \& Faun $\varnothing$, P. (1997). Clinical Findings in Competitive Swimmers with Shoulder Pain. The American Journal of Sports Medicine, 25(2), 254-260. https://doi.org/10.1177/036354659702500221

Batalha, N. M., Raimundo, A. M., Tomas-Carus, P., Barbosa, T. M., \& Silva, A. J. (2013). Shoulder Rotator Cuff Balance, Strength, and Endurance in Young Swimmers During a Competitive Season: Journal of Strength and Conditioning Research, 27(9), 2562-2568. https://doi.org/10.1519/JSC.0b013e31827fd849

Beach, M. L., Whitney, S. L., \& Dickoff-Hoffman, S. A. (1992). Relationship of Shoulder Flexibility, Strength, and Endurance to Shoulder Pain in Competitive Swimmers. Journal of Orthopaedic \& Sports Physical Therapy, 16(6), 262-268. https://doi.org/10.2519/jospt.1992.16.6.262

Carvalho, L. A. C. M., Aquino, C. F., Souza, T. R., Anjos, M. T. S., Lima, D. B. M., \& Fonseca, S. T. (2019). Clinical Measures Related to Forward Shoulder Posture: A Reliability and Correlational Study. Journal of Manipulative and Physiological Therapeutics, 42(2), 141-147. https://doi.org/10.1016/j.jmpt.2019.03.006

Cohen, J. (1988). Statistical power analysis for the behavioral sciences (2nd ed). Hillsdale, N.J: L. Erlbaum Associates.

Gozlan, G., Bensoussan, L., Coudreuse, J.-M., Fondarai, J., Gremeaux, V., Viton, J.-M., \& Delarque, A. (2006). Mesure de la force des muscles rotateurs de l'épaule chez des sportifs sains de haut niveau (natation, volley-ball, tennis) par dynamomètre isocinétique: Comparaison entre épaule dominante et non dominante. Annales de Réadaptation et de Médecine Physique, 49(1), 8-15. https://doi.org/10.1016/j.annrmp.2005.07.001

Habechian, F. A. P., Van Malderen, K., Camargo, P. R., \& Cools, A. M. (2018). Changes in shoulder girdle strength in 3 consecutive years in elite adolescent swimmers: A longitudinal cohort study. Brazilian Journal of Physical Therapy, 22(3), 238-247. https://doi.org/10.1016/j.bjpt.2018.01.001

Hajihosseini, E., Norasteh, A., Shamsi, A., \& Daneshmandi, H. (2014). The Effects of Strengthening, Stretching and Comprehensive Exercises on Forward Shoulder Posture Correction. Physical Treatments, 4(3), 123-132. 
Heinlein, S. A., \& Cosgarea, A. J. (2010). Biomechanical Considerations in the Competitive Swimmer's Shoulder. Sports Health, 2(6), 519525. https://doi.org/10.1177/1941738110377611

Hibberd, E. E., Oyama, S., Spang, J. T., Prentice, W., \& Myers, J. B. (2012). Effect of a 6-Week Strengthening Program on Shoulder and Scapular-Stabilizer Strength and Scapular Kinematics in Division I Collegiate Swimmers. Journal of Sport Rehabilitation, 21(3), 253265. https://doi.org/10.1123/jsr.21.3.253

Higson, E., Herrington, L., Butler, C., \& Horsley, I. (2018). The short-term effect of swimming training load on shoulder rotational range of motion, shoulder joint position sense and pectoralis minor length. Shoulder \& Elbow, 10(4), 285-291. https://doi.org/10.1177/1758573218773539

Johnson, J. N., Gauvin, J., \& Fredericson, M. (2003). Swimming Biomechanics and Injury Prevention: New Stroke Techniques and Medical Considerations. The Physician and Sportsmedicine, 31(1), 41-46. https://doi.org/10.3810/psm.2003.01.165

Juul-Kristensen, B., Hilt, K., Enoch, F., Remvig, L., \& Sjøgaard, G. (2011). Scapular dyskinesis in trapezius myalgia and intraexaminer reproducibility of clinical tests. Physiotherapy Theory and Practice, 27(7), 492-502. https://doi.org/10.3109/09593985.2010.528548

Kendall, F. P., McCreary, E. K., \& Provance, P. G. (2005). Muscles: Testing and Function with Posture and Pain. Lippincott Williams \& Wilkins.

Kluemper, M., Uhl, T., \& Hazelrigg, H. (2006). Effect of Stretching and Strengthening Shoulder Muscles on Forward Shoulder Posture in Competitive Swimmers. Journal of Sport Rehabilitation, 15(1), 5870. https://doi.org/10.1123/jsr.15.1.58

Larsen, C. M., Søgaard, K., Eshoj, H., Ingwersen, K., \& Juul-Kristensen, B. (2019). Clinical assessment methods for scapular positioning and function. An inter-rater reliability study. Physiotherapy Theory and Practice, 1-22. https://doi.org/10.1080/09593985.2019.1579284

Laudner, K. G., Wenig, M., Selkow, N. M., Williams, J., \& Post, E. (2015). Forward Shoulder Posture in Collegiate Swimmers: A Comparative Analysis of Muscle-Energy Techniques. Journal of Athletic Training, 50(11), 1133-1139. https://doi.org/10.4085/1062-6050-50.11.07

Ludewig, P. M., \& Cook, T. M. (2000). Alterations in Shoulder Kinematics and Associated Muscle Activity in People With Symptoms of Shoulder Impingement. Physical Therapy, 80(3), 276-291. https://doi.org/10.1093/ptj/80.3.276

Lynch, S. S., Thigpen, C. A., Mihalik, J. P., Prentice, W. E., \& Padua, D. (2010). The effects of an exercise intervention on forward head and rounded shoulder postures in elite swimmers. British Journal of Sports Medicine, 44(5), 376-381. https://doi.org/10.1136/bjsm.2009.066837

McLaine, S. J., Ginn, K. A., Fell, J. W., \& Bird, M.-L. (2018). Scapular upward rotation position is symmetrical in swimmers without current shoulder pain. Physical Therapy in Sport, 29, 9-13. https://doi.org/10.1016/j.ptsp.2017.09.003

McMaster, W. C. (1999). Shoulder Injuries in Competitive Swimmers. Clinics in Sports Medicine, 18(2), 349-359. https://doi.org/10.1016/S0278-5919(05)70150-2

O'Donnell, C. J., Bowen, J., \& Fossati, J. (2005). Identifying and Managing Shoulder Pain in Competitive Swimmers: How to Minimize Training Flaws and Other Risks. The Physician and Sportsmedicine, 33(9), $27-$ 35. https://doi.org/10.3810/psm.2005.09.195

Peterson, D. E., Blankenship, K. R., Robb, J. B., Walker, M. J., Bryan, J. M., Stetts, D. M., ... Simmons, G. E. (1997). Investigation of the Validity and Reliability of Four Objective Techniques for Measuring Forward Shoulder Posture. Journal of Orthopaedic \& Sports Physical Therapy, 25(1), 34-42. https://doi.org/10.2519/jospt.1997.25.1.34

Pink, M., Perry, J., Browne, A., Scovazzo, M. L., \& Kerrigan, J. (1991). The normal shoulder during freestyle swimming: An electromyographic and cinematographic analysis of twelve muscles. The American Journal of Sports Medicine, 19(6), 569-576. https://doi.org/10.1177/036354659101900603
Pink, Marilyn, \& Tibone, J. E. (2000). The Painful Shoulder in the Swimming Athlete. Orthopedic Clinics of North America, 31(2), 247261. https://doi.org/10.1016/S0030-5898(05)70145-0

Ramsi, M., Swanik, K. A., Swanik, C. "Buz", Straub, S., \& Mattacola, C. (2004). Shoulder-Rotator Strength of High School Swimmers Over the Course of a Competitive Season. Journal of Sport Rehabilitation, 13(1), 9-18. https://doi.org/10.1123/jsr.13.1.9

Roddey, T. S., Olson, S. L., \& Grant, S. E. (2002). The Effect of Pectoralis Muscle Stretching on the Resting Position of the Scapula in Persons with Varying Degrees of Forward Head/Rounded Shoulder Posture. Journal of Manual \& Manipulative Therapy, 10(3), 124-128. https://doi.org/10.1179/106698102790819247

Ruivo, R. M., Pezarat-Correia, P., \& Carita, A. I. (2014). Cervical and shoulder postural assessment of adolescents between 15 and 17 years old and association with upper quadrant pain. Brazilian Journal of Physical Therapy, 18(4), 364-371. https://doi.org/10.1590/bjpt-rbf.2014.0027

Serenza, F. S., Oliveira, A. S., Bedo, B. L. S., Mariano, F. P., Aquino, R., Warner, M., \& Santiago, P. R. P. (2018). Biomechanical analysis of the shoulder of swimmers after a maximal effort test. Physical Therapy in Sport, 30, 14-21. https://doi.org/10.1016/j.ptsp.2017.11.002

Su, K. P. E., Johnson, M. P., Gracely, E. J., \& Karduna, A. R. (2004). Scapular Rotation in Swimmers with and without Impingement Syndrome: Practice Effects: Medicine \& Science in Sports \& Exercise, 36(7), 1117-1123. https://doi.org/10.1249/01.MSS.0000131955.55786.1A

Tate, A., Turner, G. N., Knab, S. E., Jorgensen, C., Strittmatter, A., \& Michener, L. A. (2012). Risk factors associated with shoulder pain and disability across the lifespan of competitive swimmers. Journal of Athletic Training, 47(2), 149-158.

Thigpen, C. A., Padua, D. A., Michener, L. A., Guskiewicz, K., Giuliani, C., Keener, J. D., \& Stergiou, N. (2010). Head and shoulder posture affect scapular mechanics and muscle activity in overhead tasks. Journal of Electromyography and Kinesiology: Official Journal of the International Society of Electrophysiological Kinesiology, 20(4), 701709. https://doi.org/10.1016/j.jelekin.2009.12.003

Van de Velde, A., De Mey, K., Maenhout, A., Calders, P., \& Cools, A. M. (2011). Scapular-Muscle Performance: Two Training Programs in Adolescent Swimmers. Journal of Athletic Training, 46(2), 160-167. https://doi.org/10.4085/1062-6050-46.2.160

Wang, C.-H., McClure, P., Pratt, N. E., \& Nobilini, R. (1999). Stretching and strengthening exercises: Their effect on three-dimensional scapular kinematics. Archives of Physical Medicine and Rehabilitation, 80(8), 923-929. https://doi.org/10.1016/S00039993(99)90084-9

Weldon, E. J., \& Richardson, A. B. (2001). Upper Extremity Overuse Injuries in Swimming. Clinics in Sports Medicine, 20(3), 423-438. https://doi.org/10.1016/S0278-5919(05)70260-X

Weon, J.-H., Oh, J.-S., Cynn, H.-S., Kim, Y.-W., Kwon, O.-Y., \& Yi, C.-H. (2010). Influence of forward head posture on scapular upward rotators during isometric shoulder flexion. Journal of Bodywork and Movement Therapies, 14(4), 367-374. https://doi.org/10.1016/j.jbmt.2009.06.006 